\title{
Efeito da instilação correta de colírios sobre a pressão intra-ocular de pacientes com glaucoma
}

\author{
Effect of correct eyedropinstillation on the intraocular pressure of glaucoma patients
}

\author{
Paulo Gelman Vaidergorn ${ }^{1}$ \\ Marco Antonio de Castro Olyntho $\mathrm{Jr}^{2}$ \\ Marcelo Roco Gomes ${ }^{2}$ \\ Roberto Freire Santiago Malta ${ }^{3}$
}

Trabalho realizado no Setor de Glaucoma do Departamento de Oftalmologia do Hospital das Clínicas da Faculdade de Medicina da Universidade de São Paulo.

${ }^{1}$ Pós-graduando da Faculdade de Medicina da Universidade de São Paulo.

${ }^{2}$ Estagiário do Setor de Glaucoma do Hospital das Clínicas da Faculdade de Medicina da Universidade de São Paulo.

${ }^{3}$ Prof. Livre Docente, Divisão de Clínica Oftalmológica do Hospital das Clínicas da Faculdade de Medicina da Universidade de São Paulo.

Endereço para correspondência: Paulo Gelman

Vaidergorn - Rua Teodoro Sampaio 1812 Cj 22

São Paulo (SP) CEP 05406-150

E-mail: pgelmann@yahoo.com.br

Recebido para publicação em 21.06.2002

Aceito para publicação em 23.01.2003

Nota Editorial: Pela análise deste trabalho e por sua anuência na divulgação desta nota, agradecemos ao Dr. João Antonio Prata Jr.

\begin{tabular}{|l|}
\hline RESUMO \\
\hline Objetivo: Verificar o efeito da instilação correta de colírios hipotensores \\
oculares no comportamento pressórico de pacientes portadores de glau- \\
coma crônico. Métodos: Estudo prospectivo realizado em 90 olhos, de 47 \\
pacientes. Em cada participante era realizada uma minicurva pressórica \\
antes, e outra após lhe ser explicado como proceder à instilação correta de \\
colírios. A seguir, as médias pressóricas obtidas nas duas minicurvas eram \\
comparadas. Resultados: Houve queda significativa de $22,3 \%$ na pressão \\
intra-ocular média de 35 (38,9\%) olhos. Dos restantes, 35 (38,9\%) olhos \\
exibiram pequena queda (-8,2\%) em sua média pressórica e, 20 (22,2 \%), \\
pequeno aumento (+8,4\%), ambos não estatisticamente significantes. \\
Conclusões: Verificou-se que parcela expressiva da população estudada \\
conseguiu obter redução adicional em sua média pressórica por meio da \\
instilação correta de colírios. Portanto, o ensino da técnica adequada da \\
instilação de colírio é necessária a todos os pacientes, podendo resultar \\
em benefício extra para os usuários de medicação hipotensora ocular.
\end{tabular}

Descritores: Glaucoma/terapia; Glaucoma/complicações; Pressão intra-ocular; Prescrição de medicamentos; Soluções oftálmicas; Estudos prospectivos

\section{INTRODUÇÃO}

O tratamento clínico do glaucoma fundamenta-se, entre outras coisas, na técnica adequada do uso de colírios hipotensores. No entanto, estudos já realizados demonstram que a grande maioria dos pacientes portadores de glaucoma efetua a instilação dos colírios de modo incorreto ${ }^{(1-2)}$.

Costa et $\mathrm{al}^{(3)}$ realizaram um estudo em que verificaram a técnica da instilação de colírios em pacientes com glaucoma. Observaram que 18\% dos pacientes de sua pesquisa utilizaram duas ou mais gotas por instilação. Notaram, também, que apenas $23 \%$ deles permaneceram com os olhos fechados ou fizeram oclusão do ponto lacrimal após instilarem.

Hosoda et $\mathrm{al}^{(4)}$, estudando a técnica de instilação de colírios em uma população de pacientes com glaucoma notaram que 54,9\% deles fizeram contato da extremidade do frasco com os tecidos oculares. Tal fato, além de provocar a contaminação do frasco de colírio, estimula o piscar que, por sua vez, aumenta em até quatro vezes o fluxo de colírio para o canal lacrimal ${ }^{(1)}$. Outro fator adverso do contato do bico do frasco com a superfície ocular é o aumento do lacrimejamento reflexo ${ }^{(1)}$, que contribui para a diluir o medicamento, acarretando uma menor concentração farmacológica da droga na câmara anterior $^{(5)}$.

Zimmerman et $\mathrm{al}^{(6)}$, por outro lado, constataram que, quando realizada a compressão do ponto lacrimal ou mantidos os olhos fechados por dois 
minutos, após a instilação do colírio, a absorção sistêmica da droga reduzia-se em dois terços, enquanto que sua concentração na câmara anterior aumentava em 50\%. Este último fato, postularam, poderia aumentar a eficácia hipotensora dos medicamentos anti-glaucomatosos.

A finalidade do presente trabalho foi verificar o efeito da instilação correta de colírios em pacientes portadores de glaucoma, usuários de colírios hipotensores oculares. O objetivo foi detectar possíveis alterações na pressão intra-ocular da população estudada, após os pacientes serem instruídos como realizar a instilação com a técnica adequada. Para tanto, foram realizadas minicurvas de pressão intra-ocular antes e após a instrução adequada do uso de colírios.

\section{MÉTODOS}

A pesquisa foi realizada nos meses de março e abril de 2001 no Ambulatório do Serviço de Glaucoma da Clínica Oftalmológica do Hospital das Clínicas da Faculdade de Medicina da Universidade de São Paulo.

Para tanto, foram incluídos os pacientes portadores de qualquer forma de glaucoma primário crônico, que estivessem utilizando pelo menos um colírio hipotensor ocular há mais de um mês. Era preciso que, nos três dias imediatamente anteriores, os colírios em uso houvessem sido instilados de acordo com os horários prescritos. Foram excluídos os pacientes aos quais já houvesse sido explicada a técnica correta de instilação.

Em seguida, os pacientes eram submetidos à realização de uma primeira minicurva pressórica, que constava de quatro medidas da pressão intra-ocular (PO), às $08,11,14$ e 17 horas. Após o término da mesma, os pacientes eram instruídos como proceder à correta instilação dos colírios em uso. Ensinava-selhes a técnica de Fraunfelder ${ }^{(1)}$, que preconiza instilar uma única gota de colírio na superfície ocular sem que haja contato da extremidade do frasco com os tecidos oculares. Em seguida, fecham-se os olhos, assim devendo permanecer por dois minutos. Era dito, ainda, a cada paciente, que, para executar esta manobra, se mantivesse em posição sentada ou deitada.

Agendava-se, então, uma segunda minicurva pressórica, a ser realizada na semana seguinte. Para tanto, cada paciente era orientado a permanecer em uso da mesma medicação hipotensora ocular que utilizava quando da realização da primeira minicurva. Uma vez coletados os dados das duas minicurvas, comparou-se as medidas pressóricas obtidas.

As variáveis estudadas foram representadas por média e desvio-padrão, mediana e porcentagem. Para análise dos dados obtidos utilizou-se os seguintes testes estatísticos:

1) Teste do Qui-quadrado $\left(\chi^{2}\right)$ de Pearson

2) Análise de variância a um critério fixo (F)

3) Teste do "t" pareado

Foi adotado o nível de significância de $5 \%(0,05)$ para a rejeição da hipótese de nulidade.

\section{RESULTADOS}

No presente trabalho foram estudados 90 olhos de 49 pacientes. Destes, 47 eram olhos direitos e 43 olhos esquerdos. A idade dos participantes variou entre 30 a 84 anos, com média de $65 \pm 11,65$ anos e mediana de 67 anos.

Do total de pacientes estudados, $34(69,4 \%)$ eram do sexo feminino e 15 (30,6\%) do sexo masculino.

Em relação à raça, $29(59,2 \%)$ pacientes eram brancos, 13 $(26,5 \%)$ mulatos, $5(10,2 \%)$ negros e $2(4,1 \%)$ eram da raça amarela.

No que tange à escolaridade, dos 49 pacientes $9(18,4 \%)$ eram analfabetos, $30(61,2 \%)$ tinham o $1^{\circ}$ grau incompleto e 10 $(20,4 \%)$ tinham o $1^{\circ}$ grau completo ou mais.

O número de colírios utilizados para o controle do glaucoma, na população estudada, variou entre um e quatro, com média de 2,02 $\pm 0,81$ e mediana de dois. A análise de variância demonstrou não haver diferença estatisticamente significativa quanto ao número de colírios utilizados em olhos direitos e esquerdos $(\mathrm{F}=0,85 \mathrm{p}=0,4742)$.

Os pacientes participantes deste estudo já faziam uso de colírios para o tratamento de seu glaucoma por, em média, 6,29 \pm 5,50 anos.

Dos 90 olhos estudados, a PO média, na primeira minicurva, foi de 18,59 $\pm 3,36 \mathrm{mmHg}$, sendo de $16,66 \pm 3,41 \mathrm{mmHg}$ na segunda mini-curva. Desta forma, para o total de 90 olhos estudados, constatou-se uma redução de $1,93 \pm 2,68 \mathrm{mmHg}$ $(-10,4 \%)$ em seus níveis pressóricos médios. O teste do " $\mathrm{t}$ " pareado mostrou não haver diferença significante estatisticamente no comportamento das POs médias quando confrontados os olhos direitos e esquerdos $(t=1,49 \mathrm{p}=0,1449)$.

De acordo com a variação das médias pressóricas entre as duas mini-curvas, os olhos foram agrupados em três grupos. O primeiro grupo compreende os olhos, em número de 35 , onde a queda nos níveis pressóricos, entre a primeira e a segunda minicurvas, foi mais acentuada. Os outros dois grupos, com um total geral de 55 olhos, albergam aqueles que exibiram comportamento de suas médias pressóricas, entre as duas minicurvas, com pouca variação. Desses, 35 mostraram pequena queda nos níveis pressóricos e, 20, ligeiro aumento. A análise de variância demonstrou que as diferenças entre as médias pressóricas dos três grupos foram estatisticamente significativas $(\mathrm{F}=124,91 \mathrm{p}=0,0000001 *$ - Tabela 1$)$

\begin{tabular}{l}
$\begin{array}{l}\text { Tabela 1. Pressões intra-oculares médias na } 1^{\mathrm{a}} \text { e } \mathbf{2}^{\mathrm{a}} \text { minicurvas, } \\
\text { para cada um dos grupos e para o total de pacientes }\end{array}$ \\
\begin{tabular}{lccc} 
Grupo 1 & PIO média antes & PO média depois & \multicolumn{1}{c|}{ Diferença } \\
(35 olhos) & $19,17 \mathrm{mmHg}$ & $14,91 \mathrm{mmHg}$ & $\begin{array}{l}-4,26 \mathrm{mmHg} \\
(-22,0 \%)\end{array}$ \\
$\begin{array}{l}\text { Grupo } 2 \\
\text { (35 olhos) }\end{array}$ & $18,59 \mathrm{mmHg}$ & $17,06 \mathrm{mmHg}$ & $\begin{array}{l}-1,53 \mathrm{mmHg} \\
(-8,2 \%)\end{array}$ \\
$\begin{array}{l}\text { Grupo } 3 \\
\text { (20 olhos) }\end{array}$ & $17,57 \mathrm{mmHg}$ & $19,04 \mathrm{mmHg}$ & $\begin{array}{l}+1,47 \mathrm{mmHg} \\
(+8,2 \%)\end{array}$ \\
Total & $18,59 \mathrm{mmHg}$ & $16,66 \mathrm{mmHg}$ & $\begin{array}{l}-1,93 \mathrm{mmHg} \\
(-10,4 \%)\end{array}$ \\
PO: Pressão ocular; $\mathrm{F}=124,91 \mathrm{p}=0,0000001^{*}$ significativo
\end{tabular} \\
\hline
\end{tabular}


Verificou-se que o fato de um paciente pertencer a cada um dos três grupos acima descritos não se relacionou de forma estatisticamente significativa com o sexo $\left(\chi^{2}=2,76 \mathrm{p}=0,2522\right)$, com a idade $\left(\chi^{2}=1,50 \mathrm{p}=0,4725\right)$, com a raça $\left(\chi^{2}=10,92 \mathrm{p}=0,0907\right)$, com a escolaridade $\left(\chi^{2}=1,48 \mathrm{p}=0,8302\right)$, com o número de colírios utilizados $\left(\chi^{2}=7,35 \mathrm{p}=0,2900\right)$, ou com o tempo de uso de colírios $(\mathrm{F}=1,37 \mathrm{p}=0,2605)$. Constatou-se, também, não haver predominância estatisticamente significante de olhos direitos ou esquerdos em qualquer dos três grupos $\left(\chi^{2}=0,31 \mathrm{p}=0,8570\right)$.

\section{DISCUSSÃO}

A terapêutica clínica do glaucoma crônico se fundamenta principalmente no uso de drogas que visam reduzir a pressão intra-ocular. A fim de que tal objetivo seja atingido, utilizam-se medicações hipotensoras oculares administradas, na maioria das vezes, sob a forma de colírios.

Para o paciente portador de glaucoma faz-se preciso não somente prescrever o medicamento adequado como, também, orientá-lo quanto à utilização adequada do mesmo. Para tanto, é fundamental que o oftalmologista ensine a cada paciente a técnica correta da instilação de colírios.

Em nosso estudo, foi constatado que percentual expressivo de portadores de glaucoma crônico, usuários de colírios hipotensores, obteve uma redução adicional em seus níveis pressóricos oculares. Este efeito benéfico foi observado após os pacientes haverem sido instruídos acerca do modo correto de instilação. Ele consiste, basicamente, na técnica de Fraunfelder $^{(1)}$, que preconiza realizar a instilação sentado ou deitado (mas não de pé). Uma única gota de colírio deve ser instilada e sem que haja contato da extremidade do frasco com os tecidos oculares. Após instilar, os olhos devem permanecer fechados por, ao menos, dois minutos. Zimmerman et a ${ }^{(6)}$ recomendam a seus pacientes, nesse momento, que contem lentamente até cem, para só então abrirem os olhos.

Sabe-se que um dos itens a ser ponderado quando se analisa o comportamento da Po em pacientes com glaucoma, usuários de medicamentos hipotensores oculares, é a questão da aderência ao tratamento. A fim de minimizar este fator, foram incluídos nesta pesquisa apenas os pacientes que afirmaram ter instilado seus colírios, nos horários prescritos, nos três dias precedentes à realização das minicurvas.

Takahashi et $\mathrm{al}^{(7)}$ realizaram um estudo onde procuraram determinar a reprodutibilidade da curva tensional diária. Para tanto, realizaram duas curvas pressóricas em pacientes hipertensos oculares, em dias não consecutivos. Constataram que a média das pressões intra-oculares, na população estudada, exibiu pequena variação entre as duas curvas tensionais. Em sua pesquisa, apenas $14,3 \%$ dos olhos estudados mostrou variação, na média pressórica, superior a 15\%.

O presente trabalho verificou que $35(38,9 \%)$ dos olhos estudados obtiveram uma redução adicional, expressiva, em seus níveis pressóricos intra-oculares. Tal redução, de $22 \%$, foi considerada estatisticamente significativa. Dos 55 olhos restantes, os níveis de pressão intra-ocular variaram de modo não significativo estatisticamente. Desses, 35(38,9\%) exibiram pe- quena queda nos níveis de sua PO, enquanto que $20(22,2 \%)$, pequeno aumento. Pode-se inferir, também, que o aprendizado da técnica correta de instilação pode resultar em reduções na PO média de pacientes portadores de glaucoma independentemente de sua idade, sexo, raça, escolaridade, olho tratado e número de colírios utilizados, bem como ao tempo transcorrido desde que o paciente já usa colírios hipotensores oculares.

\section{CONCLUSÃO}

A conclusão de nosso estudo é que parcela importante da população de portadores de glaucoma pode ser beneficiada pelo conhecimento acerca do modo correto de instilar colírios. Este benefício é o de uma queda adicional em seus níveis pressóricos intra-oculares. Para tanto, é necessário que o oftalmologista ensine a técnica adequada de instilação a cada um dos pacientes aos quais prescreva colírios hipotensores oculares.

\section{ABSTRACT}

Purpose: To check the effect of correct eyedrop instillation on the intraocular pressure of chronic glaucoma patients. Methods: Prospective study with 90 eyes of 47 patients. A diurnal tension curve was performed before, and a second one after each patient was taught how to correctly instill eyedrops. The mean intraocular pressure values obtained in each tension curve were then compared. Results: There was asignificant $22.3 \%$ drop in the mean IOP levels of $35(38.9 \%)$ eyes. Of the remaining, $35(38.9 \%)$ showed a slight fall $(-8.2 \%)$, and 20 $(22.2 \%)$ a slight increase $(+8.4 \%)$, both not statistically significant.Conclusions: It was noted that an expressive part of the studied population obtained an additional fall in their mean intraocular levels by correctly instilling the eyedrops. Therefore, it is necessary to teach all patients on how to correctly perform eyedrop instillation, as that may result in an extra benefit to those using ocular hypotensive drugs.

Keywords: Glaucoma/therapy; Glaucoma/complications; Intraocular pressure; Prescriptions drug; Ophthalmic solutions; Prospective studies.

\section{REFERÊNCIAS}

1. Fraunfelder FT. Extraocular fluid dynamics: how best to apply topical ocular medication. Trans Am Ophthalmol Soc 1976;74:457-61

2. Kass MA, Hodapp E, Gordon M, Kolker AE, Goldberg I. Patient administration of eyedrops. Part 11. Observation. Ann Ophthalmol1982,14:889-93.

3. Costa Vital P, Vasconcellos JPC, Pelegrino M, Kara-José N. Análise da técnica de instilação de colírios por pacientes glaucomatosos. Rev Bras Oftalmol 1995;54:523-8.

4. Hosoda M, Yamabayashi S, Furuta M, Tsukahara S. Do glaucoma patients use eyedrops correctly? J Glaucoma 1995;4:202-6.

5. Shell JW. Pharmacokinetics of topically applied ophthalmic drugs. Surv Ophthalmol 1982;26:207-18.

6. Zimmerman TJ, Kooner KS, Kandarakis AS, Ziegler LP. Improving the therapeutic index of topically applied ocular drugs. Arch Ophthalmol 1984; 102:551-3

7. Takahashi WY, Susanna Jr R, Betinjane AJ. Reproducibilidade da curva tensional diária em dias não consecutivos. Arq Bras Oftalmol 1979;42:277-8. 